Hackler, C., Byse, E., Hoots, A., and Boughner, J. 2020. "Customizing Lean Leadership: New Facilitator Case Studies." In: Tommelein, I.D. and Daniel, E. (eds.). Proc. $28^{\text {th }}$ Annual Conference of the International Group for Lean Construction (IGLC28), Berkeley, California, USA, doi.org/10.24928/2020/0107, online at iglc.net.

\title{
CUSTOMIZING LEAN LEADERSHIP: NEW FACILITATOR CASE STUDIES
}

\author{
Cory Hackler ${ }^{1}$, Erika Byse ${ }^{2}$, Adam Hoots ${ }^{3}$, and Jeanne Boughner ${ }^{4}$
}

\begin{abstract}
This paper presents the fourth issuance of Building a Lean Culture with a Lean Leadership (LL) training program initiated by the company. So far, the LL program has reached over five hundred participants. Over the last year, the program "grew" new passionate facilitators who then taught their Business Units and Departments. These new facilitators engaged with their students at a much deeper level by applying the concepts specifically to meet their needs. The connection was cultivated organically because both the teachers and students had a personal and professional relationship already in place from working together. This paper shares success stories from the new facilitators on how their teams, in the company's value stream, applied LL knowledge to their business. The concepts were applied in a variety of ways including go to the Gemba as a customer strategy for computer specialists, who typically work in the office. Transforming the company's business includes all leaders teaching LL as a key part of their skillsets to improve organizational health.

The program's main goal is to disseminate lean through the company to support "the Leadership model" described by Howell (Howell et al. 2004) which is "coaching and continual fostering of an organizational environment conducive to building trust among people for collaboration, learning, and innovation".
\end{abstract}

\section{KEYWORDS}

Lean leadership, change, action learning, collaboration, trust.

\section{INTRODUCTION}

The Lean Leadership Program (LL) started in 2015 with the goal of creating a culture of sustained learning and leadership at the company, and has been discussed previously in the IGLC community (Hackler et al. 2017, 2018, 2019). However, the year 2019 was a breakthrough year for the LL because graduates of the course became the teachers of the content. As noted in Seed's (2014) paper, the new project manager "requires project leaders who possess group facilitation skills, organizational management skills, people assessment and change management skills, along with the tactical skills of the past" and LL helps individuals grow these team building skills. One of the qualities exceptional

1 Lean Leader/Trainer/Coach, DPR Construction, Phoenix, AZ 85034, USA, coryha@dpr.com, orcid.org/0000 0002-8098-8172

2 Lean Leader/Trainer/Coach. DPR Construction, Phoenix, AZ 85034, USA, erikab@dpr.com, orcid.org/0000-0003-3902-2533

3 Lean Leader, DPR Construction, Charlotte, NC 28217, USA, adamhoots@gmail.com, orcid.org/00000002-0383-8437

4 Leader of ERP Technology, DPR Construction, Charlotte, NC 28217, USA, jeanne@dpr.com, orcid.org/0000-0002-0298-7190 
leaders share is the ability to teach others how to work better together, and LL has made this possible by educating individuals on this skill set. LL meetings are held over virtual meetings that are necessary to plant the seed of lean concepts, because it is through these group facilitations, that leaders create a "customized" training session for the team (Hackler et al. 2017). Two examples that illustrate this approach are described through the experiences of two lean advocates who graduated from the LL course earlier this year, became LL facilitators. Author4 is the manager of the Enterprise Resource Programs (ERP), and her team supports the company's core software. After graduating from the LL course, she decided to take her team of fifteen individuals, spread across the country through the class. Author3 and a colleague took their business unit on the East coast through the course, the first two to initiate a team-teaching approach. The weekly "action learning meetings" (Alves et al. 2010) have evolved to the higher level where the facilitators and group leads can "question participants about their managerial problems and require participants to commit to bringing a solution to be discussed with the group" as opposed to the previous years of more general discussions.

While our metrics to measure success may not be conventional, this paper describes first-hand accounts from LL graduates. One former student commented, "before I was firefighting, where now I've been able to switch into process improvement mode. No longer am I exhausted at the end of the day." The reader will also be exposed to how the course has been built around the idea of PDCA (plan, do check, adjust). This involves asking people doing the work how to improve the content. These types of feedback loops have determined how the content is improved prior to each round of registration.

\section{LEAN LEADERSHIP PRINCIPLES}

$\begin{array}{ll}\text { (1) Lean vs. Traditional } & \text { (7) Value Stream Thinking } \\ \text { (2) Principles and Purpose } & \text { ( }) \text { Effective Measurement } \\ \text { (3) Focus/Alignment/Constancy } & \text { 9 } \text { Reflection } \\ \text { (4) Student and Teacher } & 10 \text { Leader Standard Work } \\ \text { (5) Inquiry and Advocacy } & \text { (II) Go See - Leadership } \\ \text { (6) Respect/No Blaming People } & \text { (12) Building Teams } \\ \text { (13 Advocating Lean Thinking. Mitigating Resistance }\end{array}$

Figure 1: Lean Leadership principles

The following stories reference the thirteen lean leadership principles (Gran et al. 2012), which are also integral to the lean leadership curriculum. The curriculum is from Leancor's "Lean Leadership Virtual Certificate Course". The content was bought from Leancor in 2016 allowing us to adopt and customize the content with each round. They are summarized below:

1. Lean vs Traditional: demonstrates the main differences between a lean thinker and a traditional thinker.

2. Principles and Purpose: provides clarity on overarching goals of ways in which lean supports and communicates purpose of said business. 
3. Focus/Alignment/Constancy: teaches how to align the team around the voice of the customer, both internal and external.

4. Student and Teacher: discusses the learning opportunities between colleagues with years of experience and newly hired individuals.

5. Inquiry and Advocacy: discusses the challenge of dealing with "difficult" people by using inquiry to understand other points of view.

6. Respect/No Blaming People: describes how to create a safe environment where everyone has a voice.

7. Value Stream Thinking: allows individuals to better understand the overarching entirety of a job through analysing all batch processes.

8. Effective Measurement: holds people accountable to commitments made for the success of the entire team.

9. Reflection: provides opportunities for continuous improvement, looking for ways to improve through PDCA [plan, do, check, adjust].

10. Leader Standard Work: teaches students how to schedule standard work times to increase the value of production.

11. Go See Leadership: identifies the value in seeing the work where the work is being done before making decisions. Visual management is part of this lesson.

12. Building Teams: discusses the valuable cycle involving team formation which includes forming, storming, norming and performing of teams.

13. Advocating Lean Thinking and Mitigating Resistance: students will face resistance and should plan see change from another's point of view.

The following three stories are examples of how the thirteen-lean leadership (LL) concepts have profoundly engrained themselves in the company's core values, as well as influenced employees on a wide range of skillsets. This string of stories proves the power in learning; if an educator can influence another person's life by improving the way they live and/or think, the educator is truly driving deep rooted growth.

\section{LEAN LEADERSHIP: THE NEXT CHAPTER}

\section{STORY 1: EAST COAST}

Authors 1 and 2 have been teaching 28 rounds of LL and realized that more facilitators were needed to reach more people especially with the company's rapid growth. Additionally, the content was organized in such a way that others could facilitate the course after graduating. We approached Author3 about starting a local lean leadership course. Author 3 and a colleague had recently graduated the course and were now ready to take the next step - teaching the content to a local group of students. The two met at length to discuss this new role and were concerned that they would not be able to maintain consistency in delivering the lean message. As a result, Author1 and Author2 assured them that they would assist however needed in order to support their efforts of teaching. After this conversation and reviewing the curriculum and outline, the two decided to move forward with teaching the course. During this time, Author3 surveyed his/her business unit, asking question about how teams could improve their projects. The results provided the lean teachers with insight into business unit issues and how to better use the thirteen disciplines to provide training and address the feedback they received. From there, the two new instructors registered twenty-five new students. This grassroots approach of 
leading by example is described in the lean leader is a student and a teacher principle four and is one of the key ingredients for the continued success of the entire LL team.

Within the first couple weeks of the course, eight people were unable to commit to the time requirement necessary to complete the course work. The instructors immediately began checking in with the rest of the students, to ensure continued support and commitment from the remaining students. This is an example of how principle six is integral to being a lean leader and to the course continuing to succeed. In addition, the instructors began to observe how familiar their students were with one another, as they all worked in the same region. Because of this familiarity, students were able to personally hold each other accountable [principle 8] when it came to completing homework and implementing concepts learned in the class. As the students progressed, they began to better understand one another and develop a synchronized language and common understanding of lean and it's benefits within the company. Using this common language, their teams began to realize how to get more work done in less time, an example of principle 10. This course also enabled the group to develop a deeper sense of trust independently, within their team, and throughout their business unit, principle 12 in action.

Over time, Author3 came to realize that facilitating the course was difficult for the two instructors in addition to their regular responsibilities, as it amounted to an additional four hours of work per week. In an attempt to increase their standard work output, the new instructors decided to recruit help/additional lean leaders. They began to reach out to other graduates in their local area and were overwhelmed by the response. Eight previous graduates volunteered their time to help support the two lean leaders. After brainstorming ways to divide the workload of the ten-week program, they decided to split the content evenly between the ten instructors. This allowed them to organically practice principle 4 by leading as a student and a teacher. This approach to learning while educating worked so well that other business units are planning on copying this delivery model in 2020.

The most powerful part of this LL course story is that it led to five additional stories of how lean is spreading throughout the company and the organization. In addition, this group of LL has decided to meet once a quarter to conduct job site visits (Gemba Walks). The idea of the Gemba Walk is to extract the pockets of excellence from each of their project teams that currently exist and spread this profound wisdom throughout the entire business unit, thus driving the concept of creating a learning organization. Some of the "pockets of excellence" include:

- issuing documents to help clarify roles and responsibilities for newly hired employees, aligning with principle 3

- using the principles to discuss and vote to implement leader standard work and go see leadership to save time and reduce stress

- applying go see leadership to various roles, including office/admin roles which help employees create more powerful visual controls to communicate information

- positive impact of principles in, not only professional lives, but also personal lives: reducing stress, better communication, walking in someone else's shoes/empathy, sharing stories, insights, experiences, improved quality of life

Author3 realized several things at the end of this adventure. The course was hard to complete as a student but even more challenging as a teacher. The understanding of the content needs to be much richer and much deeper embedded into the standard way of 
working. They realized that they were still just at the beginning of their lean journey and have a long way to go. Running a course in their business unit has embedded the concepts on most jobs that they work on. It has given everyone a common language to drive people/purpose then process and hold people accountable to doing what they say they are going to do. It has been a great experience and they are looking forward to the many more rounds to come.

\section{Story 2: Facilitating My Enterprise Resource Planning Team}

Author4 was first exposed to Lean Leadership when a co-worker decided to go through the training. She spoke of it with such enthusiasm and excitement, it gave Author4 a sense of missing out on something important. About a month later, Author4 was informed that the business unit would be hosting a LL course. Without hesitating, she signed up and was determined to make the time needed to complete the course. At first, she struggled to see how the content was applicable to her day-to-day office job, but after the second session, she began to see the value. Upon completing the course, she quickly realized that the rest of her team needed to sign up as well. As with any team, the demands on their time is great and finding the 'right time' to engage in this course would be challenging. However, she understood the value of what they could learn as a team, so she looked at shifting priorities to make it a reality, applying principle 7 .

The team manages and supports the company's ERP (Enterprise Resource Program). Their team is unique because they consist of a variety of roles such as Technology Project Managers, System Business Analysts, Application Support Personnel, Developers, and Quality Assurance Specialists, and are geographically dispersed. They oversee the dayto-day use of the ERP by performing system administration and maintenance, application support, managing and supporting over seventy data integrations with dozens of thirdparty solutions, and implementing new functionality and key features. This team is also responsible for supporting Marketing, Finance and Accounting technologies, this can entail new software implementations, acting as trusted advisors on business processes, and general support. Author4 engaged Author 1 and inquired if they could facilitate a LL cohort that was tailored to a group in a non-construction environment.

This course was important to the team for a variety of reasons. First, they were already doing things that were lean, so this learning could reinforce already familiar concepts. An example of this is they use A3s to provide project updates, strengthening this lean concept would help them realize that they are already using lean skills. Second, they wanted to provide the team with tools, a common language and understanding of how they can effectively work together. For example, help identify waste by paying attention and pausing when work adds value and when it does not. Author 4 was excited about the opportunity, so they decide to incorporate a LL kick-off face-to-face meeting. It is crucial to note that Author4 decided to throw out the original agenda of the meeting to make this kick-off (Figure 2) happen. 


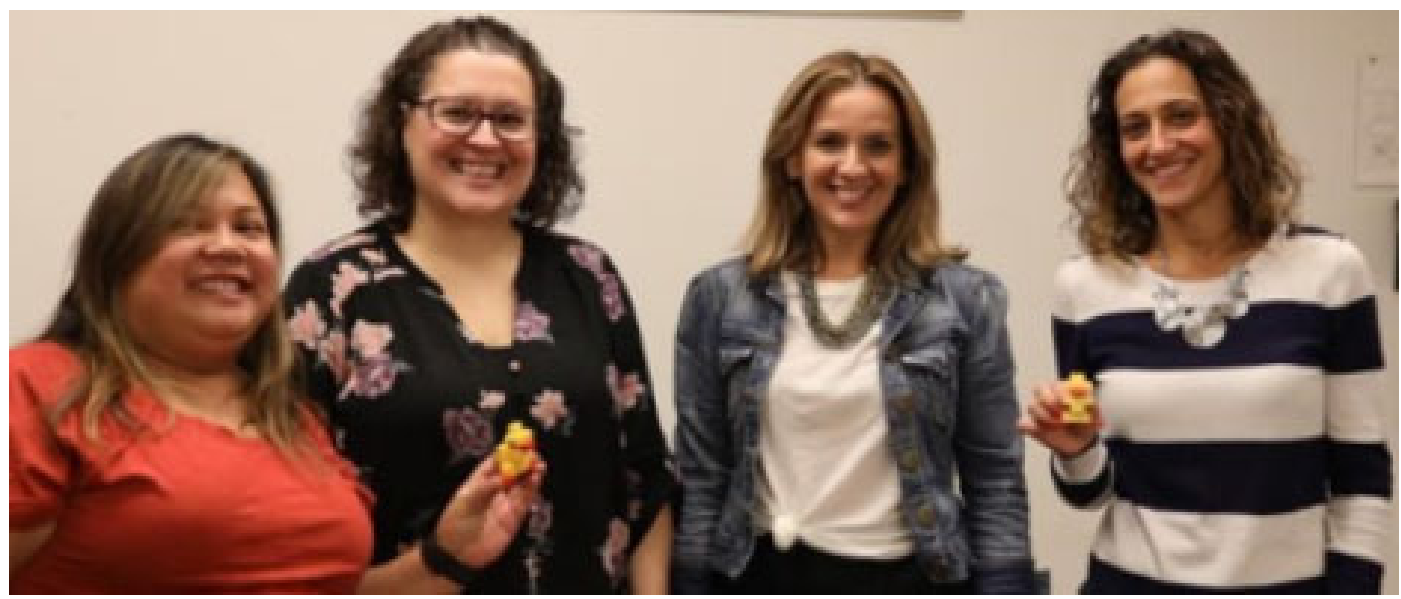

Figure 2: Lean Leadership Kick-off for ERP Team - Team building Simulation

Author4 would love to say that the team was super excited about going through this course from the beginning, but initially there were not. While the team loved the in-person kickoff with Authorl which included interactive activities, Author4 began to encounter resistance from her team about the amount of homework and the general time commitment. She was even told that her priorities were out of whack because there were other things going on that were more important than the team learning Lean. Thankfully, Author4 spoke to each of these individuals and encouraged them to stick with it. If something in their workload was going to be negatively impacted by the additional learning, she would personally make sure the work would be taken care of.

As the weeks went on, the team began to embrace what they were hearing and learning. In addition, team members were starting to use lean terms in their team and project meetings. They were also beginning to hold each other accountable by saying things like "remember what we learned in our lean class last week, let's give that a try," or "let's focus on looking at the process, not the person. For Author4 who had already been through the class, leading the conversations gave her even greater insight into the material and concepts. During the sessions, she also recruited other lean leaders within the organization to help facilitate some of the group calls in order to continue easing the time commitment.

Author4 is proud to say that all twelve individual that started the lean journey graduated eleven weeks later! $100 \%$ completion was an entirely different outcome than Author 1 and Author2 were seeing in the national offering they were teaching. Teaching and support of leadership was a huge key to this success and something all educators in the course are learning from. Every participant recognized the value in the time that they had invested into the course. To celebrate, Author 1 and 4 wanted to incorporate what the team learned into something they could take away by practicing principal 6 respect for people. A big part of this conversation has involved the encouragement of principal 11 go see for the office-based team. In addition to all graduates receiving a certificate of completion, the authors gifted them a 'go-see kit' and a personalized letter. The kit included safety gear that they can wear when they visit jobsites to see how work is accomplished. This reinforced the importance of going to where the work is done and asking your customers for input to be an active part of the solution. 


\section{Story 3: Training Delivery CuSTOMization}

In order to increase the number of LL students each year and encourage new facilitators, the curriculum developers have applied the PDCA cycle to improve the content and delivery. Our capability of reaching students has increased from 28 in 2016 to 269 last year as shown in Table 1.

Table 1: Building Teaching Capacity

\begin{tabular}{ccc}
\hline Year & Student Graduates & New Hires \\
\hline 2015 Pilot & 17 & 551 \\
2016 & 28 & 551 \\
2017 & 33 & 729 \\
2018 & 228 & 805 \\
2019 & 269 & 1000 estimate \\
Total & $\mathbf{5 7 5}$ & \\
\hline
\end{tabular}

Every year, the students are asked what is working and what is not in each round. The instructors take the information and make improvements to the content and delivery. The content is adapted to meet the requirements of the learners (internal customers) by eliminating wasteful curriculum, adding the construction perspective, and adding improved technology.

As described in previous papers (Hackler et al. 2017, 2018, 2019), the Leancor Lean Leadership Virtual Certificate Course content (Gran et al 2012) was transferred to our Learning platform to manage registration and standardize the delivery. This immediately eliminated students from dropping the class out of sheer frustration. OneNote and virtual meeting software were our original choices for teaching the content each week. Another cloud-based option was surfacing across the company when the instructors first investigated the new platform, they found that it was challenging to change from what they knew and were comfortable with to something new. This is the exact issue that every lean educator experiences when working on the adjust part of PDCA.

The company recognized the value in the course, so they decided to continue through the valley of despair, when things get worse before they become better, only to discover that switching platforms was the right choice. Now the instructors had the means to break the classes of twenty-five into small groups of five. Volunteers lead each of the groups which added accountability for students to complete their homework and attend the check-ins. Each leader role became critical to ensure every member understood and met the expectations. To maintain organization amongst teams, each group is assigned a color allowing the instructors to easily identify the groups when calling on them to report on their apply your learning. For example, the instructor might say "what does the yellow group think" when discussing the lesson. Using the platform allowed for conversations eliminating e-mail waste (Figure 3). 


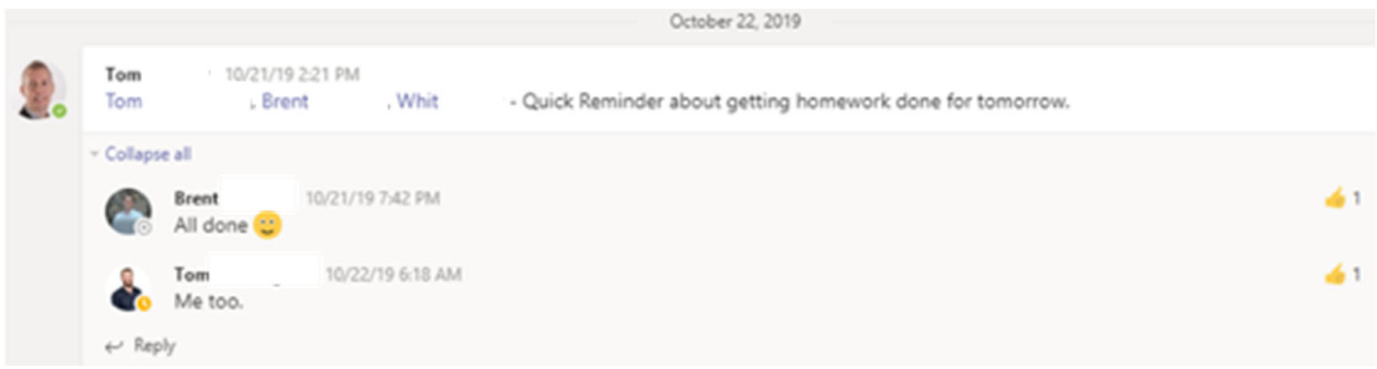

Figure 3: Teams Conversation on Accountability

The last big change the new technology brough was the ability to have five different groups engage in virtual meetings at the same time, but in different "classrooms" (Figure 4). During this time, groups meet for the first fifteen minutes to discuss the week's learning topics. After the set time, each small group re-joins the master call with the entire class and instructors. This portion of the call enable students to share the conversation they had in the break-out discussions, as instructors lead a conversation on specific concepts and how to apply them. Admittedly, technology is usually the last think we tell people makes a difference, but in this case, it has allowed the same two people to do twice the amount of work while still having time to meet their own demanding workload. This platform will allow class sizes to increase $30 \%$ and keep the personal touch by breaking into groups of five.

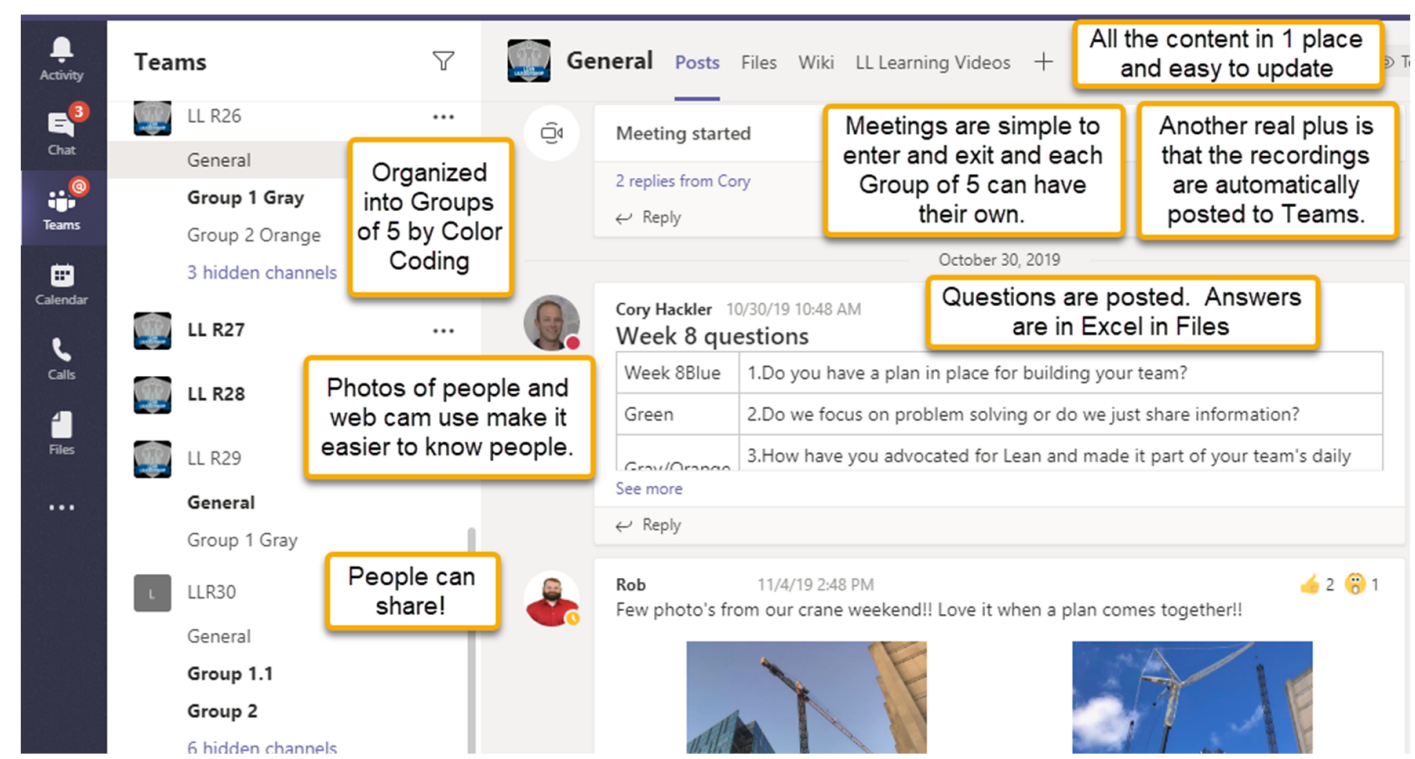

Figure 4: Platform for Five Virtual Meetings Concurrently

The last part of this system involves communication. Lean is more than just a training class, it is a system of interconnected parts that make a lean organization. The Ecosystem (Figure 5) is a visual of the company's belief in how interconnected parts strengthen the unit. It is called an Ecosystem because the entire system is affected when one part fails or weakens. 


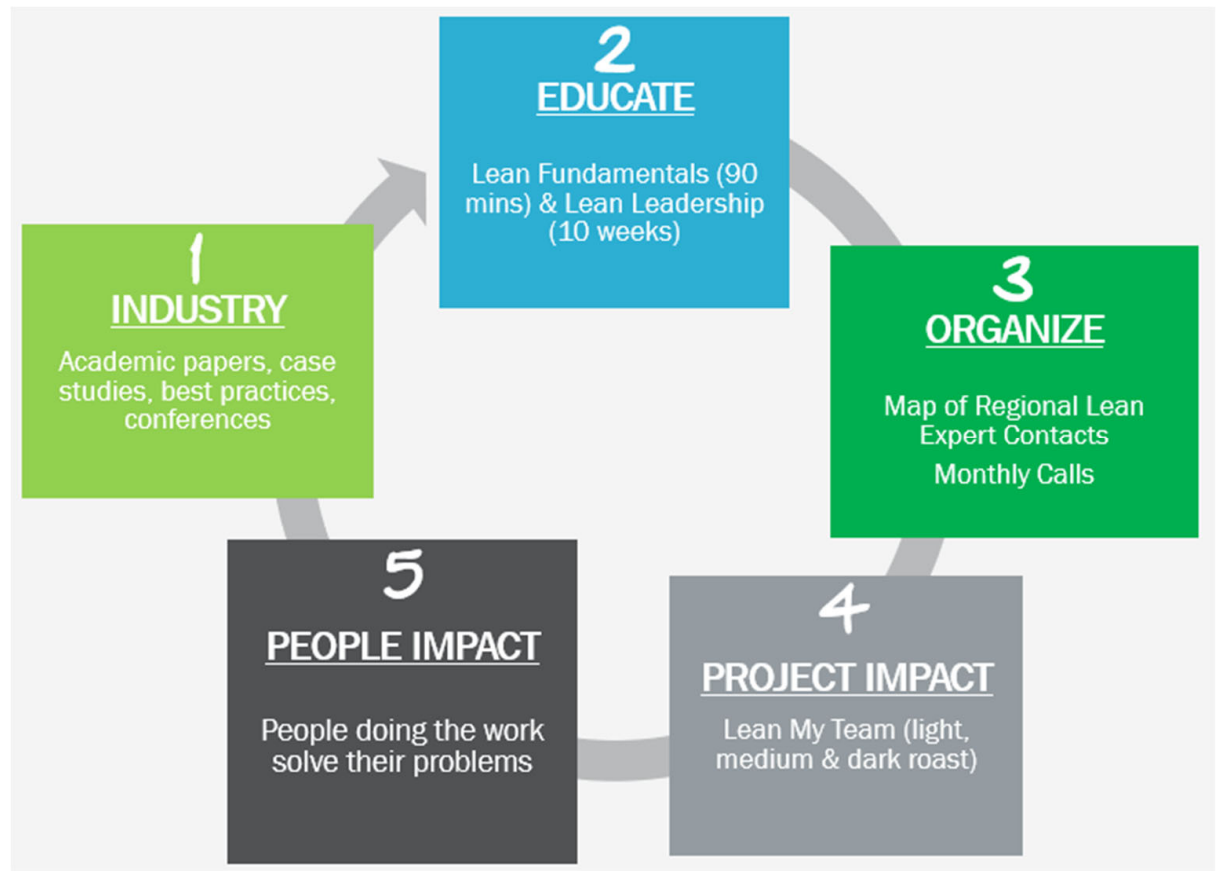

Figure 5: Platform for Five Virtual Meetings Concurrently

\section{DISCUSSION AND FUTURE}

These stories should demonstrate to others that the time invested in the content can drastically improve an individual's quality of life, both personally and professionally. The more we "leanify" the course, and our lives, the more improved each part of the system and the unit will be. This will also result in facilitators spending less time checking in one-on-one with students and more time adding value to the content and course. In 2020, students will take a first-time offered "leanifed" class which involves less outside content. This version focuses more on the content that is specific to the roles, positions, and work within the industry which participants have been requesting (Hackler et al. 2017, 2018, 2019). Student feedback, along with an increase in recruited facilitators, will verify if the content and the flipped classroom method is working. This method encourages students to complete background building assignments prior to attending class, so that the class time is less about learning the material and more about applying the material. The goal is that every team, including external customers, hosts their LL course as part of forming and storming of developing high performance teams.

\section{CONCLUSIONS}

Adding new facilitators to the LL training has helped people bond together around one common goal, the implementation of the thirteen principles. While these two stories by Author3 and Author4 share similarities, they are also quite different. Author3's story is field specific, but Author4's story is not. The common thread is that the thirteen concepts can be successfully applied to any role/position within the company. In addition, the value in both learning and educating is integral to becoming a high performing team member, a concept that is highlighted in the course. The training helps to break down the silos, or separate entities that individual within the company can develop without the training. Participants of the LL are given the opportunity to see the work through a lean lens. The 
training enables people, in different business units, to recognize the company's shared vision and work together to achieve it. As evidenced in the stories, the training also provides students with the knowledge necessary to analyse, question, collaborate, and redesign their processes to improve flow of information and work through the entire value stream. The partners are writing their own story on how they are using the LL training to improve their businesses.

How do we know LL is making a difference? As we conclude this paper, enrolment for rounds thirty-one, thirty-two and thirty-three filled up in just a few hours. Additionally, Authrol was invited to share these journeys with the entire LCI community. His presentation had the largest number of enrolled participants to date. As is true of most shared experiences, the concerns around cultivating a lean culture are also bringing people together by encourage individuals to share their challenges and their successes in the hopes that each story will inspire others on their lean journey.

According to Alves et al. (2010), academics play a major role in bridging the gap between the theories of lean and their implementation and practical execution impacts require further study. We hope this paper provides more information on what lean and look forward to the discussions that will follow.

\section{ACKNOWLEDGMENTS}

The authors would like to acknowledge the efforts of those who have participated in the training and helped redefine this journey. The views, comments, and opinions expressed in this paper are those of the authors and do not represent those of the company.

\section{REFERENCES}

Alves, T., Milberg, C., Walsh, K. (2010). "Exploring Lean Construction Practice, Research, and Education." Proc. $18^{\text {th }}$ Ann. Conf. Int. Group for Lean Construction, Haifa, Israel.

Gran S., Martichenko R., Miller W., Pearce R. (2012). "PEOPLE A leader's day-to-day guide to building, managing and sustaining lean organizations." Leancor.

Hackler C., Byse E., Alves, T.C.L., and Reed D., (2018). "Lean Leadership training: lessons from a learner-centered analysis." Proc. $26^{\text {th }}$ Ann. Conf. Int. Group for Lean Construction, Chennai, India, pp. 484-494.

Hackler C., Byse E., Alves, T.C.L., and Reed D. (2019). "Building a Lean Culture: Engaging the Value Stream." Proc. $27^{\text {th }}$ Ann. Conf. Int. Group for Lean Construction, Dublin, Ireland, pp. 169-178.

Hackler C., Byse E., Reed D., and Alves, T.C.L. (2017). "Building a Lean Culture" In: Proc. LC3 2017 and 25 th Ann. Conf. Int. Group for Lean Construction, Volume II, Heraklion, Greece, pp. 309-316.

Howell, G. Macomber, H., Koskela, L., and Draper, J. (2004), "Leadership and Project Management: Time for a Shift from Fayol to Flores." Proc. $12^{\text {th }}$ Ann. Conf. Int. Group for Lean Construction, Heslingør, Denmark.

Seed, W.R. (2014). "Integrated Project Delivery Requires a New Project Manager." Proc. $22^{\text {nd }}$ Ann. Conf. Int. Group for Lean Construction, Oslo, Norway, 1447-1459. 